\title{
One-step synthesis of the PdPt bimetallic nanodendrites with controllable composition for methanol oxidation reaction
}

\author{
Yuan Zhang, Jinfeng Zhang, Zelin Chen, Yunwei Liu, Mengmeng Zhang, Xiaopeng Han, \\ Cheng Zhong, Wenbin $\mathrm{Hu}$ and Yida Deng*
}

\begin{abstract}
This paper demonstrates a one-pot approach to produce highly dispersed dendritic palladium-platinum bimetallic nanoparticles (NPs) with small particle size, tunable composition and high catalytic activity. Herein, the PdPt bimetallic NPs have been obtained using bayberry tannin (BT) as both the reducing agent and surfactant. Additionally, the PdPt bimetallic NPs with different Pd/Pt atomic ratios can be prepared by just varying the amounts of the $\mathrm{Pd}$ and Pt precursors. Most importantly, the as-prepared $\mathbf{P d}_{52} \mathbf{P t}_{48}$ catalyst exhibits the optimal catalytic activities compared with the other compositional PdPt NPs $\left(\mathbf{P d}_{82} \mathbf{P t}_{18}, \mathbf{P d}_{69} \mathbf{P t}_{31}\right.$, and $\mathbf{P d} d_{36}$ $\left.\mathrm{Pt}_{64}\right)$ and commercial $\mathrm{Pt} / \mathrm{C}(20 \mathrm{wt} . \%)$ catalyst for the methanol oxidation reaction (MOR). Meanwhile, $\mathrm{Pd}_{52} \mathbf{P t}_{48}$ also shows better $\mathrm{CO}$ tolerance, which can be attributed to the unique dendritic structure and the synergistic effect between Pd and Pt. With evident advantages of the facile preparation and enhanced catalytic performance, it holds great promise as a high-performance catalyst for electrochemical energy conversion.
\end{abstract}

Keywords: one-pot approach, bayberry tannin, dendritic nanoparticles, controllable composition, methanol oxidation electrocatalysis

\section{INTRODUCTION}

With the world's growing demand for new resources that can be used as substitutes for the traditional fossil fuels, much attention has recently been given to proton exchange membrane fuel cells (PEMFCs). This is because they are ideal candidates for use in portable devices and are excellent alternatives that offer clean energy [1-3]. As we all know, Pt is the best catalyst of all pure metals for the PEMFCs [4]. However, it is hindered by the limited reserves, high cost, and its poor resistance to $\mathrm{CO}$ poisoning despite the high activity [5]. One of the most effective strategies to solve this problem is to produce bimetallic Pt nanocrystals containing low-cost transition metals, which can effectively reduce the loading amount of $\mathrm{Pt}$ and improve catalytic activities ascribed to the synergistic effect between the two metals.

Based on this case, various structures have been successfully generated for Pt-based bimetallic nanostructures in a wide range of elements, such as PtPd [6-11], PtCu [12,13], PtAg [14], PtCo [15,16], PtAu [17,18], PtNi [19 -21], PtRu [22-25], and PtFe [26]. By comparison, given that Pd and Pt have nearly the same structures (the same group of the periodic table, the face-centered cubic (fcc) crystal structure and the similar lattice constants) $[27,28]$, the PdPt bimetallic nanoparticles (NPs) are especially attractive for catalyzing multiple reactions due to the presence of the powerful catalytic components of $\mathrm{Pd}$ and Pt. Meanwhile, the incorporation of Pd into Pt-based bimetals can not only significantly reduce the cost of the catalysts by decreasing the amount of $\mathrm{Pt}$, but also enhance the catalytic properties while reducing the $\mathrm{CO}$ poisoning effect due to a strong coupling between these two metals $[8,29]$.

In order to develop PdPt catalysts with the enhanced $\mathrm{Pd}$ utilization and catalytic activity and durability, PdPt catalysts with a variety of morphologies were prepared, especially for the dendritic nanostructures, which have attracted increasing interest [6,7,9-11,30-32]. This special nanostructure can give rise to more catalytically active sites, such as boundaries and corner atoms, providing a high surface area in catalytic reactions. For example, the PdPt nanodendrites were acquired by following a facile

Tianjin Key Laboratory of Composite and Functional Materials, School of Materials Science and Engineering, Tianjin University, Tianjin 300372, China

* Corresponding author (email: yida.deng@tju.edu.cn) 
aqueous synthetic method reported by Zhou et al. [6], Yamauchi et al. [11], and Zhang et al. [30]. Regretfully, the catalytic performance toward methanol oxidation reaction (MOR) is far from meeting the application demands owing to the inapparent dendritic structure [6] and relatively large particle size [30]. Later, Lu et al. [7] synthesized the hollow Pt-on-Pd nanodendrites via a template approach, which employed a complicated preparation process. Moreover, the mass activity of the asobtained PtPd catalysts for MOR in the case was $275.2 \mathrm{~mA} \mathrm{mg}_{\mathrm{Pt}}{ }^{-1}$. This was too low to meet the current requirement due to the larger particle size although a hollow interior was successfully prepared. Meanwhile, the PtPd nanodendrites were usually prepared by a seedmediated growth strategy, in which the produced $\mathrm{Pd}$ nanoparticles first served as the seeds $[9,10]$. So undoubtedly, the main challenge in the synthesis of the PdPt nanoparticles with higher activity and stability is the difficulty involved in designing an economical and rational approach.

In this study, we described a one-step route to synthesize the PdPt bimetallic NPs with the assistance of bayberry tannin (BT) as reducing agent and surfactant. We provided a convenient and environmentally friendly approach without organic solvent and premade seeds. The dendritic PdPt bimetallic NPs with different compositions $\left(\mathrm{Pd}_{82} \mathrm{Pt}_{18}, \mathrm{Pd}_{69} \mathrm{Pt}_{31}, \mathrm{Pd}_{52} \mathrm{Pt}_{48}\right.$, and $\left.\mathrm{Pd}_{36} \mathrm{Pt}_{64}\right)$ were prepared by adjusting the molar ratio between the $\mathrm{Pd}$ and Pt precursors (Table S1). The electrocatalytic results revealed that these dendritic PdPt catalysts exhibited higher catalytic property than that of commercial $\mathrm{Pt} / \mathrm{C}$ catalyst toward the MOR. This result can be attributed to the high surface area with greatly promising active sites and to the synergistic effect of the two metals. Particularly, the $\mathrm{Pd}_{52} \mathrm{Pt}_{48}$ catalysts showed the optimal catalytic performance and an enhanced $\mathrm{CO}$ tolerance compared with other compositional PdPt catalysts.

\section{EXPERIMENTAL SECTION}

\section{Chemicals and materials}

Chloroplatinic acid hexahydrate $\left(\mathrm{H}_{2} \mathrm{PtCl}_{6} \cdot 6 \mathrm{H}_{2} \mathrm{O}\right.$, analytical grade) and perchloric acid $\left(\mathrm{HClO}_{4}, 70 \%\right)$ were purchased from Sinopharm Chemical Reagent Co., Ltd. Palladium (II) chloride ( $\mathrm{PdCl}_{2}$, analytical grade) was bought from Alfa Aesar. Bayberry tannin (BT, 99\%) was purchased from Adamas Reagent Co., Ltd. Nafion perfluorinated resin solution (5 wt.\% in a mixture of lower aliphatic alcohols and water, contains $45 \%$ water) was prepared from Sigma Aldrich, Co., Ltd. The commercial
Pt/C (20 wt.\%) catalyst was purchased from Shanghai Hesen Electric Co., Ltd., and the commercial PtRu/C (20 wt.\% Pt, 10 wt.\% Ru) catalyst was obtained from Sigma Aldrich. The isopropanol alcohol was bought from Tianjin Commie Chemical Reagent Co., Ltd. Methanol $\left(\mathrm{CH}_{3} \mathrm{OH}, 99.5 \%\right)$ was purchased from Aladdin Industrial Corporation. All reagents were used without further purification. Deionized water (Milli-Q) was used for the synthesis of nanocrystals and during the centrifugal process.

\section{Preparation of PdPt catalysts}

To prepare the dendritic PdPt bimetallic nanoparticles, $3 \mathrm{~mL}$ of $5 \mathrm{mmol} \mathrm{L}^{-1} \mathrm{H}_{2} \mathrm{PtCl}_{6} \cdot 6 \mathrm{H}_{2} \mathrm{O}, 1 \mathrm{~mL}$ of $10 \mathrm{mmol} \mathrm{L}^{-1}$ Pd precursor $\left(0.5 \mathrm{mmol} \mathrm{L}^{-1} \mathrm{PdCl}_{2}\right.$ dissolved into $\mathrm{HCl}$ with mole ratio of 1:2 to obtain Pd precursor solution), and $0.085 \mathrm{~g}$ BT were dissolved in $26 \mathrm{~mL}$ deionized water, after which the mixture was continuously stirred for $15 \mathrm{~min}$ at room temperature. Afterwards, the resultant homogeneous brown-yellow solution was transferred into a $50 \mathrm{~mL}$ Teflon-lined stainless steel autoclave, which was treated at $120^{\circ} \mathrm{C}$ for $6 \mathrm{~h}$ and then cooled down to room temperature by furnace cooling. Finally, the resulting product was collected by centrifugation at $18,000 \mathrm{rpm}$ for $15 \mathrm{~min}$, and washed five times with the mixture of deionized water and ethanol. The composition of PdPt NPs can be rationally adjusted by changing the volume of the different precursors added in the synthesis (Table S1).

\section{Materials characterization}

Transmission electron microscope (TEM) images, elemental analysis mapping, and line-scanning were recorded by a JEOL JEM-2100F with an acceleration voltage of $200 \mathrm{kV}$. Samples for TEM were prepared by dropping one drop of the NPs in water dispersion on a carboncoated copper grid (200 mesh). The crystal structure of the samples was characterized using a D8 Advanced Xray diffraction equipment (XRD, $\mathrm{Cu} \mathrm{Ka}$, radiation, $\lambda=$ $1.5406 \AA$ ). The inductively coupled plasma-mass spectrometry (ICP-MS) and energy-dispersive spectrometer (EDS) were used to measure the composition of the nanocrystals. The surface composition and electronic structure of the samples were characterized by X-ray photo electron spectroscopy (XPS, Kratos AXIS Ultra DLD). The plasma cleaner (PDC-002-HP (230V)) were used to clean the surface of the particles.

\section{Electrocatalytic measurements}

The methanol oxidation experiments were carried out using a conventional three-electrode system, which con- 
tained a glassy carbon electrode with a diameter of $5 \mathrm{~mm}$ as the working electrode for electrochemical measurements. The counter and reference electrodes were a $\mathrm{Pt}$ plate and an $\mathrm{Ag} / \mathrm{AgCl}\left(3 \mathrm{~mol} \mathrm{~L}^{-1} \mathrm{KCl}\right)$ electrode, respectively. To prepare a catalyst-coated working electrode, the suspension in isopropyl alcohol and water (1:1) was dropcoated onto the polished electrode surface, followed by drying at room temperature. Afterward, the catalyst was covered with $8 \mu \mathrm{L}$ of Nafion solution ( 0.2 wt.\%) to ensure that the catalyst was tightly attached to the electrode surface during the electrochemical measurements. Then, the electrode was dried at room temperature. The electrode was cleaned by a plasma cleaner before the characterization. The metal loading of the prepared PdPt and commercial $\mathrm{Pt} / \mathrm{C}, \mathrm{PtRu} / \mathrm{C}$ catalysts on the working electrode were both $35.7 \mu \mathrm{g} \mathrm{cm}^{-2}$ according to the ICP data.

The electrochemically active surface areas (ECSAs) were measured by cyclic voltammograms (CVs) in an $\mathrm{N}_{2}{ }^{-}$ saturated $0.1 \mathrm{~mol} \mathrm{~L}^{-1} \mathrm{HClO}_{4}$ solution at a scan rate of $50 \mathrm{mV} \mathrm{s}^{-1}$ by cycling the potential between 0.076 and $1.1 \mathrm{~V}$ ( $v s$. reversible hydrogen electrode (RHE)). The ECSAs were calculated by the following equation: ECSA $=Q_{\mathrm{H}} / m \times 210$, where $Q_{\mathrm{H}}$ is the charge in the $\mathrm{H}_{\text {upd }}$ (underpotential deposited hydrogen) adsorption-desorption area obtained after the double layer correction region between 0.151 and $0.351 \mathrm{~V}$ ( $v s$. RHE), $m$ is the Pt loading amount on the electrode, and $210 \mu \mathrm{C} \mathrm{cm}^{-2}$ is the charge required for the monolayer adsorption of hydrogen on the Pt surface. For methanol oxidation, the CVs and chronoamperometry curves were recorded in a mixture solution of $0.1 \mathrm{~mol} \mathrm{~L}^{-1} \mathrm{HClO}_{4}$ and $1 \mathrm{~mol} \mathrm{~L}^{-1} \mathrm{CH}_{3} \mathrm{OH}$ solution at a sweep rate of $50 \mathrm{mV} \mathrm{s}^{-1}$. The CVs were obtained with the potential range of $0.256-1.256 \mathrm{~V}$ ( $v s$. RHE). For the CO stripping measurements, high-purity $\mathrm{CO}\left(99.99 \% v / v\right.$ in purity) was purged into the $0.1 \mathrm{~mol} \mathrm{~L}^{-1}$ $\mathrm{HClO}_{4}$ electrolyte for 20 min to obtain a maximum coverage of $\mathrm{CO}$ on the $\mathrm{Pt}$ active sites. Then, the dissolved $\mathrm{CO}$ was excluded by bubbling Ar gas (99.99\% $v / v$ in purity) for $20 \mathrm{~min}$. Three consecutive CVs were recorded between 0.076 and $1.1 \mathrm{~V}\left(v s\right.$. RHE) at $50 \mathrm{mV} \mathrm{s}^{-1}$.

\section{RESULTS AND DISCUSSION}

The dendritic PdPt catalysts were synthesized in an aqueous solution at $120^{\circ} \mathrm{C}$ for $6 \mathrm{~h}$. The TEM image of the as-obtained $\mathrm{PdPt}$ nanoparticles with the $\mathrm{Pd}_{52} \mathrm{Pt}_{48}$ composition is illustrated in Fig. 1a. As can be seen, these PdPt NPs are distributed uniformly with the dendritic shape. High resolution TEM (HRTEM) images (Fig. 1b, c) taken from several subunits clearly show the well-resolved fringes with lattice spacing of $0.225 \mathrm{~nm}$ (1)),

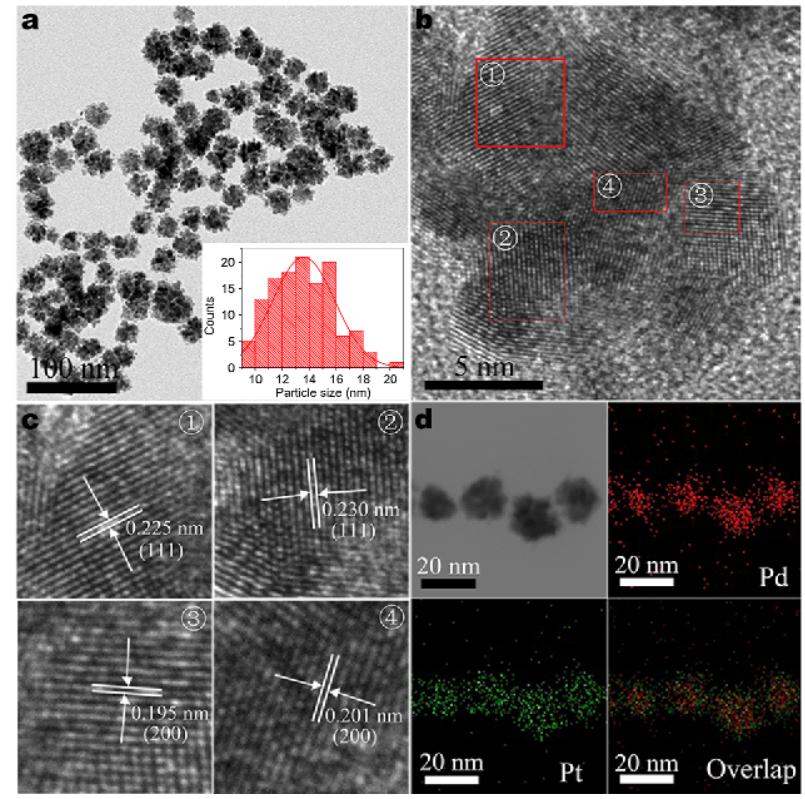

Figure 1 (a) TEM image and the size distribution (inset) of the $\mathrm{Pd}_{52} \mathrm{Pt}_{48}$ NPs. (b) and (c) HRTEM images of the $\mathrm{Pd}_{52} \mathrm{Pt}_{48}$ NPs. (d) EDX mapping images of Pd and Pt elements.

$0.230 \mathrm{~nm}$ (2) and $0.195 \mathrm{~nm}$ (3), $0.201 \mathrm{~nm}$ (4)), which can be indexed to the $\{111\}$ and $\{200\}$ crystal facets of the fcc PdPt NPs. Moreover, the lattice distances are slightly different from an individual metal Pd or Pt due to the production of the bimetallic NPs $[33,34]$. As seen in Fig. $1 \mathrm{~d}$, the energy-dispersive X-ray (EDX) elemental mapping images of $\mathrm{Pd}$ and Pt elements indicate the formation of a Pt-on-Pd structure consisting of Pd-rich core and Pt shell. Based on the dendritic morphology and small size, the NPs can present a high surface area, which is beneficial for improving the catalytic mass activity.

In order to determine the formation mechanism of the dendritic PdPt NPs, the effect of time on the morphology was investigated (Fig. 2 and Scheme 1). A large number of tiny irregular nanocrystals $(4.8 \mathrm{~nm}$ ) (Fig. 2a and Fig. S1) formed in the initial stage of the reaction $(15 \mathrm{~min})$. The BT (Fig. S2) served as the reductant which chelated with $\mathrm{Pd}(\mathrm{II})$ and $\mathrm{Pt}(\mathrm{IV})$ ions through its adjacent phenolic hydroxyl groups (Fig. S2b). Then, the Pd(II) and Pt(IV) ions are reduced to $\mathrm{Pd}$ and $\mathrm{Pt}$ atoms, while the phenolic hydroxyl groups are inductively oxidized to the corresponding quinones (Fig. S2c) [35-37]. Due to the excessive BT, Pd(II) and $\mathrm{Pt}(\mathrm{IV})$ ions can be reduced as much as possible although tannin may partially be oxidized to quinones under air atmosphere. However, because of the relatively faster reduction rate of $\mathrm{Pd}$ precursor compared with that of Pt [38], the preferential 


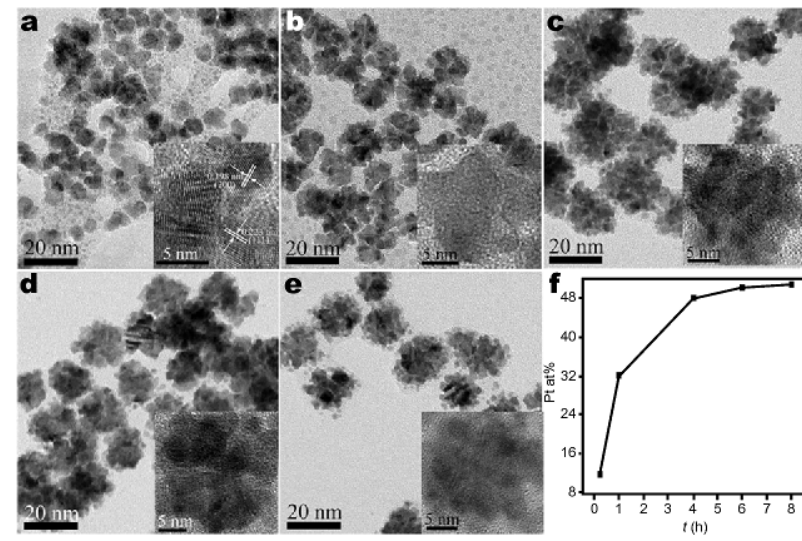

Figure 2 TEM and HRTEM images (inset) of the $\mathrm{Pd}_{52} \mathrm{Pt}_{48}$ NPs collected at different growth stages: (a) $15 \mathrm{~min}$, (b) $1 \mathrm{~h}$, (c) $4 \mathrm{~h}$, (d) $6 \mathrm{~h}$ and (e) $8 \mathrm{~h}$. (f) The content of Pt varies with the reaction time.
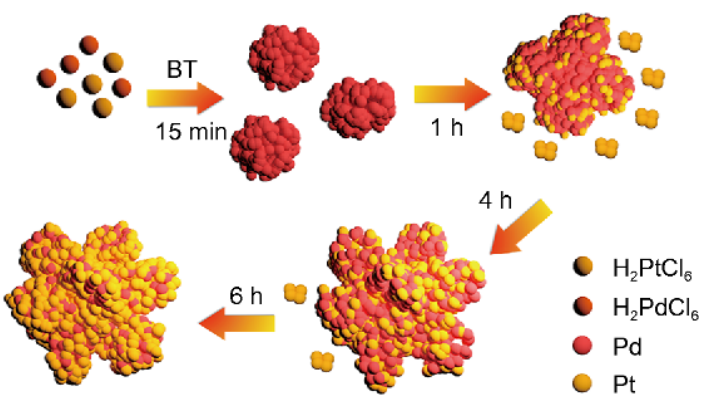

Scheme 1 The schematic illustration of the $\mathrm{Pd}_{52} \mathrm{Pt}_{48} \mathrm{NP}$ formation.

nucleation and growth of Pd lead to the prospective initial generation of the Pd-rich NPs, which is consistent well with the TEM-EDS results showing the atomic percentage of Pd is almost 88 at.\% in the early stage (Table S2 and Fig. 2f). The interplanar spacings with 0.223 and $0.198 \mathrm{~nm}$ are observed in the inset at the bottom right in Fig. 2a, which are close to the $\{111\}$ and $\{200\}$ lattice spacing of the fcc Pd crystal, respectively, further demonstrating the formation of the Pd-rich nanoparticles. When the reaction time was increased to $1 \mathrm{~h}$ (Fig. 2b), Pd core was preferentially formed, and then Pt atoms deposited on the outer surface of Pd core due to the intrinsic high surface free energy and interatomic bond energy [39]. As a result, the dendritic PdPt structure with increasing particle size (15.2 $\mathrm{nm}$ ) and Pt content (Fig. 2f) was formed due to the deposition of newly formed $\mathrm{Pt}$ atoms in an island growth mode on the Pd core surface (Scheme 1).

After $4 \mathrm{~h}$, the particle size increased to $19 \mathrm{~nm}$ along with the Pt content (Fig. 2c and Fig. S1, respectively), which can be ascribed to the growth of the Pd core and the deposition of $\mathrm{Pt}$ atoms side from the reduction of $\mathrm{Pt}$ precursors by $\mathrm{BT}$ via a chemical reaction that induced $\mathrm{Pt}$ atoms to form in an island pattern. With a further increase in reaction time to $6 \mathrm{~h}$ (Fig. $2 \mathrm{~d}$ ), Pt atoms can also be achieved by the galvanic displacement reaction between $\mathrm{Pd}$ atoms and $\mathrm{Pt}$ precursors $\left(2 \mathrm{Pd}+2 \mathrm{Cl}^{-}+\mathrm{PtCl}_{6}^{2-}\right.$ $\left.\rightarrow \mathrm{Pt}+2 \mathrm{PdCl}_{4}{ }^{2-}\right)$. This phenomenon contributes to a decrease in size $(18.2 \mathrm{~nm}$ ) with increasing Pt content due to the similar size of the Pd and Pt atoms [27,28]. After $8 \mathrm{~h}$, no significant changes can be observed in the size, composition, and shape of the PdPt NPs (Fig. 2e), confirming the complete reaction within $6 \mathrm{~h}$. The XRD patterns of the products obtained at different reaction stages are shown in Fig. S3, revealing an obvious shift of the pure Pt with the increased reaction time, which is also in agreement with the EDS composition analysis and the previous description (Fig. 2f).

The crystal structure, chemical composition, and electronic properties of the $\mathrm{Pd}_{52} \mathrm{Pt}_{48}$ catalyst were further characterized by XRD, TEM-EDS, and XPS. Fig. 3a shows four diffraction peaks corresponding to (111), (200), (220), and (311), respectively, which are positioned between the pure Pt (JCPDS No. 87-640) and Pd (JCPDS No. 87-637) crystal phases, thereby suggesting the generation of PdPt NPs. The Pd/Pt atomic ratio was confirmed as about 52:48 by both TEM-EDS (49.8:50.2, Fig. $3 \mathrm{~b})$ and ICP-MS (51.9:48.1, Table S3). Fig. 3c, d display the respective XPS spectra of $\mathrm{Pd} 3 \mathrm{~d}$ and $\mathrm{Pt} 4 \mathrm{f}$ for the asobtained $\mathrm{Pd}_{52} \mathrm{Pt}_{48}$ and commercial $\mathrm{Pt} / \mathrm{C}$ catalysts. The binding energies (BE) of $\mathrm{Pd}_{52} \mathrm{Pt}_{48} \mathrm{NPs}$ are located at 335.21 and $340.76 \mathrm{eV}$ for the $3 \mathrm{~d}_{5 / 2}$ and $3 \mathrm{~d}_{3 / 2}$, respectively, whereas those peaks are located at 335.01 and $340.31 \mathrm{eV}$ for the pure Pd sample, respectively (Fig. 3c). Such positively shifted values indicate that the $\mathrm{Pd}$ in $\mathrm{Pd}_{52} \mathrm{Pt}_{48}$ catalyst is present in a different electronic environment, possibly due to the charge transfer of the PdPt catalyst [6,34]. Likewise, this change in the electronic structure of $\mathrm{Pd}$ and $\mathrm{Pt}$ is also responsible for the negative shift of $\mathrm{Pt} 4 \mathrm{f}$ BEs (Fig. 3d) compared with that of $\mathrm{Pt} / \mathrm{C}$ catalyst. Specifically, Pt would draw electrons from Pd due to the larger electronegativity of $\mathrm{Pt}$ (2.28) compared with that of $\operatorname{Pd}(2.20)$ [40]. The change would then cause partial filling of the Pt $5 \mathrm{~d}$ bands, resulting in a downshift of the d-band center [41].

In addition, the similar PdPt NPs with other $\mathrm{Pd} / \mathrm{Pt}$ atomic ratios were prepared by simply tuning the molar ratio of the Pd and Pt precursors (Table S1). In the present synthesis system, the amount of Pt precursors plays an important role in the formation of the dendritic PdPt nanocrystals. When the composition was $\mathrm{Pd}_{82} \mathrm{Pt}_{18}$ ac- 

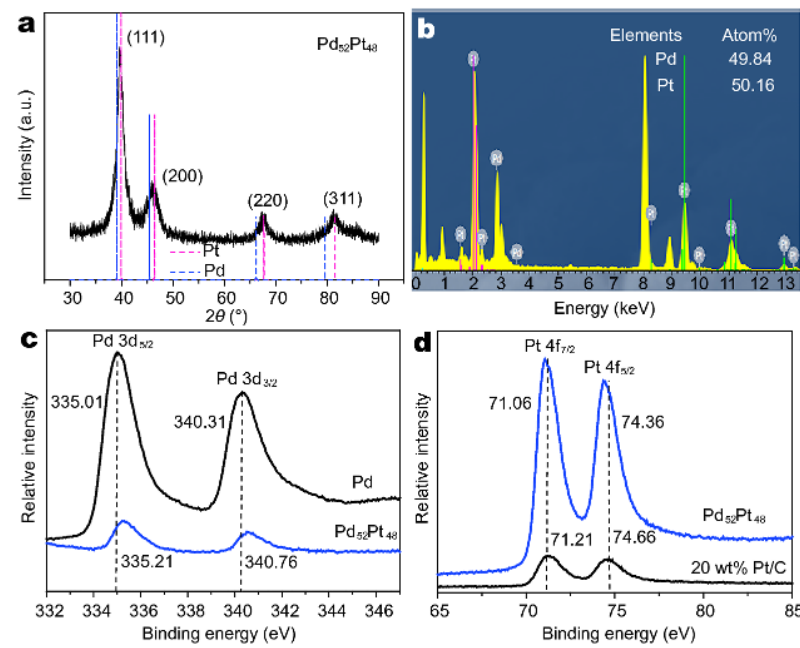

Figure 3 (a) XRD patterns of the as-prepared $\mathrm{Pd}_{52} \mathrm{Pt}_{48}$ catalyst. The drop-lines are the standard peaks for Pt (pink) and Pd (blue) from the JCPDS. (b) TEM-EDS pattern of the $\mathrm{Pd}_{52} \mathrm{Pt}_{48}$ catalyst. (c) Pd $3 \mathrm{~d}$ XPS spectrum of the $\mathrm{Pd}_{52} \mathrm{Pt}_{48}$ NPs and bulk Pd. (d) Pt $4 \mathrm{f} \mathrm{XPS} \mathrm{spectrum} \mathrm{of} \mathrm{the}$ $\mathrm{Pd}_{52} \mathrm{Pt}_{48}$ and commercial $\mathrm{Pt} / \mathrm{C}$ catalysts.

cording to both EDS and ICP-MS (Table S3), the monodisperse NPs with an average size of $13.6 \mathrm{~nm}$ were observed, as presented in Fig. 4a and Fig. S4.

Nevertheless, only small irregular particles with no obvious dendritic structure in this case were obtained, which resulted from less Pt atoms deposited onto the preferential nucleated Pd core surface due to the insufficient amount of the Pt precursors. With the increasing amount of the Pt precursors, the dendritic $\mathrm{Pd}_{69} \mathrm{Pt}_{31}$ NPs were formed (Fig. $4 \mathrm{~b}$ ), and the size of the nanocrystals ranged narrowly from 10 to $26 \mathrm{~nm}$, with an average diameter of $19.2 \mathrm{~nm}$ (Fig. S4). This result is due to the subsequently direct nucleation and growth of $\mathrm{Pt}$ atoms on the central Pd core surface as mentioned previously. When the ratio of the $\mathrm{Pd}$ and $\mathrm{Pt}$ precursors changed to 2:3 (Fig. 4c), the overall atom percentage of $\mathrm{Pt}$ in the nanocrystals was $48.2 \%$, as measured by ICP-MS, corresponding to a composition of $\mathrm{Pd}_{52} \mathrm{Pt}_{48}$. Furthermore, the obtained dendritic morphology which can provide more active sites were barely changed compared with $\mathrm{Pd}_{69} \mathrm{Pt}_{31}$ NPs. As illustrated in Fig. 4d, the dendritic $\mathrm{Pd}_{36} \mathrm{Pt}_{64}$ catalysts with an average size of $17.7 \mathrm{~nm}$ were obtained, and the sufficient Pt precursors more thoroughly facilitated the galvanic replacement reaction between $\mathrm{Pd}$ atoms and $\mathrm{PtCl}_{6}^{2-}$. This result will contribute greatly to the understanding of the decrease of PdPt particle size. Nonetheless, owing to the balance of the replacement reaction, $\mathrm{Pd}$ atoms cannot be replaced by $\mathrm{Pt}$

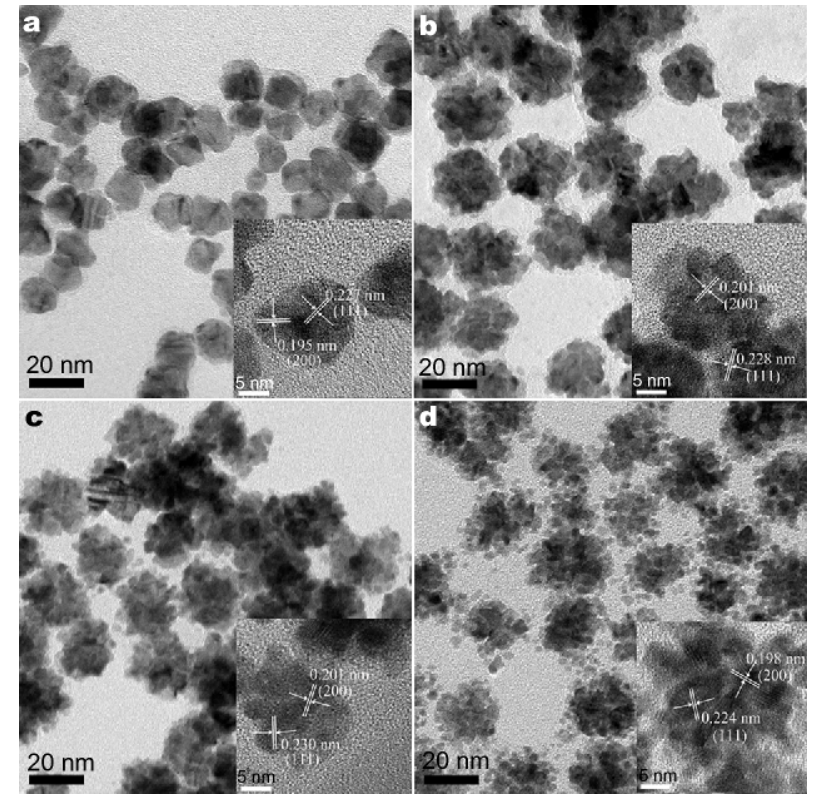

Figure 4 TEM and HRTEM (inset) images of the (a) $\mathrm{Pd}_{82} \mathrm{Pt}_{18}$, (b) $\mathrm{Pd}_{69}$ $\mathrm{Pt}_{31}$, (c) $\mathrm{Pd}_{52} \mathrm{Pt}_{48}$, and (d) $\mathrm{Pd}_{36} \mathrm{Pt}_{64}$ NPs.

atoms absolutely. It can also be seen that some small particles distribute around the PdPt NPs, which can be ascribed to the spontaneous self-nucleation and growth of $\mathrm{Pt}$ atoms partially due to the increased content of the $\mathrm{Pt}$ precursors. In order to further reveal the detailed structure of these NPs, the corresponding HRTEM images are shown in the inset, indicating the growth of Pt branches at multiple sites on the Pd core. The measured interplanar spacing suggests the formation of PdPt NPs, which are mainly exposed by the $\{111\}$ and $\{200\}$ planes of the fcc PdPt nanostructure.

The XRD patterns were used to characterize the structure of these PdPt NPs, as presented in Fig. 5. All catalysts show four diffraction peaks corresponding to the fcc structure. Specifically, the peaks corresponding to the (111) plane of different PdPt NPs with increasing ratio of Pt are located at approximately $39.2^{\circ}, 39.4^{\circ}, 39.6^{\circ}$, and $39.8^{\circ}$ respectively, showing a small shift to higher $2 \theta$ values. This shift results from the lattice expansion due to the incorporation of the larger Pt atoms into the Pd lattice [42].

To measure the ECSA of the PdPt NPs with different $\mathrm{Pd} / \mathrm{Pt}$ atomic ratios, their $\mathrm{CVs}$ in an $\mathrm{N}_{2}$-saturated $0.1 \mathrm{~mol} \mathrm{~L}^{-1} \mathrm{HClO}_{4}$ solution at a scan rate of $50 \mathrm{mV} \mathrm{s}^{-1}$ were conducted, as illustrated in Fig. 6a and Fig. S5a. From the hydrogen adsorption/desorption charges in the CV curves, the ECSA of the catalysts were calculated (Fig. 6b) to be $37.8,31.3,40.1,21.3,52.1$ and $50.7 \mathrm{~m}^{2} \mathrm{~g}_{\mathrm{Pt}}{ }^{-1}$ for 

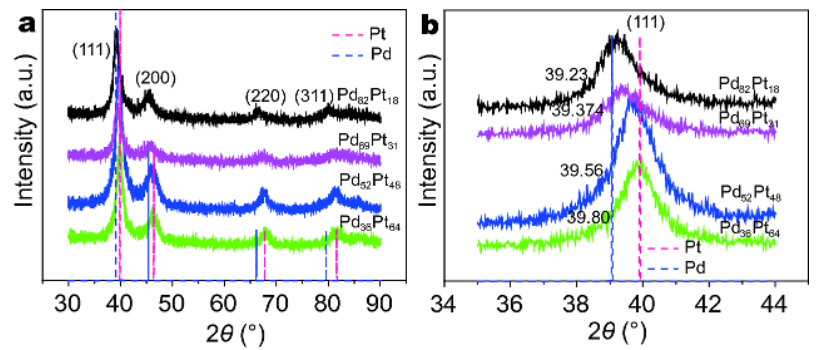

Figure 5 (a) XRD patterns of the $\mathrm{Pd}_{82} \mathrm{Pt}_{18}, \mathrm{Pd}_{69} \mathrm{Pt}_{31}, \mathrm{Pd}_{52} \mathrm{Pt}_{48}$, and $\mathrm{Pd}_{36} \mathrm{Pt}_{64} \mathrm{NPs}$. The drop-lines are the standard peaks for Pt (pink) and $\mathrm{Pd}$ (blue). (b) Enlarged XRD patterns in the range of $2 \theta=35^{\circ}-44^{\circ}$.
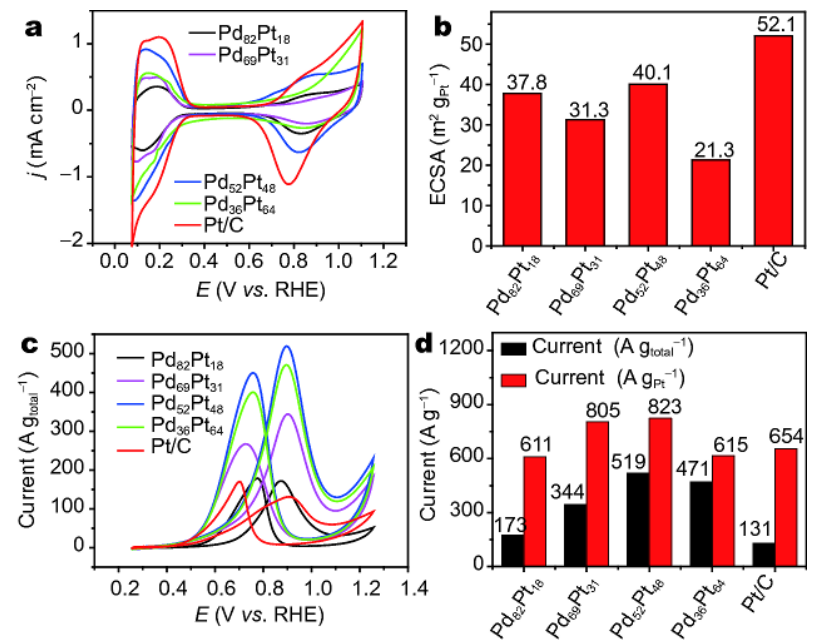

Figure 6 (a) $\mathrm{CV}$ curves in $\mathrm{N}_{2}$-saturated $0.1 \mathrm{~mol} \mathrm{~L}^{-1} \mathrm{HClO}_{4}$ solution at a scanning rate of $50 \mathrm{mV} \mathrm{s}^{-1}$. (b) The ECSA of the catalysts. (c) CV curves in the $0.1 \mathrm{~mol} \mathrm{~L}^{-1} \mathrm{HClO}_{4}+1 \mathrm{~mol} \mathrm{~L}^{-1} \mathrm{CH}_{3} \mathrm{OH}$ solution at a scan rate of $50 \mathrm{mV} \mathrm{s}^{-1}$. (d) The MOR activity per unit mass of Pt (red bars) and per unit mass of metals (black bars).

$\mathrm{Pd}_{82} \mathrm{Pt}_{18}, \mathrm{Pd}_{69} \mathrm{Pt}_{31}, \mathrm{Pd}_{52} \mathrm{Pt}_{48}, \mathrm{Pd}_{36} \mathrm{Pt}_{64}, \mathrm{Pt} / \mathrm{C}$, and $\mathrm{PtRu} / \mathrm{C}$, respectively. As for the $\mathrm{PtRu} / \mathrm{C}$ catalyst, due to the surface dilution effect by $\mathrm{Ru}[43,44]$, it has relatively lower ECSA than that of $\mathrm{Pt} / \mathrm{C}$ catalyst.

The catalytic activities of the samples toward MOR compared with commercial $\mathrm{Pt} / \mathrm{C}$ and $\mathrm{PtRu} / \mathrm{C}$ catalyst were investigated in the solution of $0.1 \mathrm{~mol} \mathrm{~L}^{-1} \mathrm{HClO}_{4}+$ $1 \mathrm{~mol} \mathrm{~L}^{-1} \mathrm{CH}_{3} \mathrm{OH}$ at a scan rate of $50 \mathrm{mV} \mathrm{s}^{-1}$ (Fig. $6 \mathrm{c}$ and Fig. S5b, respectively). For the $\mathrm{Pd}_{82} \mathrm{Pt}_{18}$ catalyst, the relatively small size of these NPs is beneficial for the increase of the MOR activity, but the irregular structure without dendritic morphology is unfavorable. Therefore, these two factors make the activity of $173 \mathrm{~A} \mathrm{~g}_{\text {total }}^{-1}$, which is relatively low. For the $\mathrm{Pd}_{69} \mathrm{Pt}_{31}$ catalyst, the activity was estimated to be $344 \mathrm{~A} \mathrm{~g}_{\text {total }}{ }^{-1}$. The higher value relative to the former can be attributed to the dendritic structure providing larger surface area as well as high Pt content. It should be noted that the $\mathrm{Pd}_{52} \mathrm{Pt}_{48}$ catalyst displays the maximum peak current of $519 \mathrm{~A} \mathrm{~g}_{\text {total }}{ }^{-1}$, which is almost 4 and 1.3 times higher than those of commercial $\mathrm{Pt} / \mathrm{C}$ $\left(131 \mathrm{~A} \mathrm{~g}_{\text {total }}{ }^{-1}\right)$ and PtRu/C (403 A g metal $^{-1}$ ) catalysts, respectively. Additionally, the $\mathrm{Pd}_{52} \mathrm{Pt}_{48}$ catalyst has the largest specific ECSA, which can be attributed to the electronic coupling between the two metals. The $\mathrm{Pd}_{52} \mathrm{Pt}_{48}$ catalyst also has a large dendritic structure that provides a larger surface area, further confirming that the electrocatalytic activity can be optimized when the atomic percentage of $\mathrm{Pt}$ is about $50 \%$ in our case. Compared with the commercial $\mathrm{Pt} / \mathrm{C}$ catalyst, the enhanced activity arises from the synergistic effect with $\mathrm{Pd}$ as well as its high surface area. With a further increased content of the $\mathrm{Pt}$ precursors $\left(\mathrm{Pd}_{36} \mathrm{Pt}_{64}\right)$, the MOR activity was calculated to be $471 \mathrm{~A} \mathrm{~g}_{\text {total }}{ }^{-1}$, resulting from the branched structure with the highly exposed surface and active sites that was beneficial to MOR. In brief, the arrangement difference of the surface atoms for the bimetallic PdPt nanocrystals can readily lead to the activity change for MOR, although they have the similar shape and size. This observation is consistent with the structure-sensitive reaction $[21,45]$ for MOR. Similarly, based on the per unit mass of $\mathrm{Pt}$, the MOR activity increases with $\mathrm{Pd} / \mathrm{Pt}$ ratio and then declines (Fig. 6d, red bars).

The $\mathrm{Pd}_{52} \mathrm{Pt}_{48}$ catalyst shows the highest activity (823.4 $\left.\mathrm{A} \mathrm{g}_{\mathrm{Pt}}{ }^{-1}\right)$, which is almost 1.26 and 1.36 times larger than that of the commercial $\mathrm{Pt} / \mathrm{C}\left(654 \mathrm{~A} \mathrm{~g} \mathrm{gt}_{\mathrm{Pt}}{ }^{-1}\right)$ and $\mathrm{PtRu} / \mathrm{C}$ (604.1 $\mathrm{A} \mathrm{g} \mathrm{gt}_{\mathrm{Pt}}{ }^{-1}$ ) catalysts, respectively. In methanol oxidation, $\mathrm{Pd}$ and $\mathrm{Pt}$ are mainly responsible for the water dehydrogenation (Pd-OH formation) and methanol dehydrogenation (Pt-CO formation), respectively. The reaction between $\mathrm{Pd}-\mathrm{OH}$ and $\mathrm{Pt}-\mathrm{CO}$ produces $\mathrm{CO}_{2}$ and regains the active metal surface, which is favorable for reducing the electronic binding energy in $\mathrm{Pt}$ and improving catalytic activity. This is also significantly co-affected by both the $\mathrm{Pt} / \mathrm{Pd}$ ratio and their reaction dynamics. In the case of the lack of Pd, the water dehydrogenation on Pt occurs at a higher potential, making the overall oxidation process on pure Pt sluggish [34]. Thus, the activity of the $\mathrm{Pd}_{36} \mathrm{Pt}_{64} \mathrm{NPs}$ is lower than that of the $\mathrm{Pd}_{52} \mathrm{Pt}_{48}$ catalyst despite the high Pt content. The activity also decreases with the presence of the excessive Pd on account of the lack of Pt for methanol dehydrogenation, as seen in the MOR catalysis of the $\mathrm{Pd}_{82} \mathrm{Pt}_{18} \mathrm{NPs}$. Moreover, according to XPS data for the $\mathrm{Pd}_{52} \mathrm{Pt}_{48}$ catalyst, the negative shift for the binding energy of Pt occurred. As is well known, the shift in binding energies is associated with the variation in the d-band center [41]. The 
resulting downshift d-band center of Pt can be ascribed to the electronic interactions of $\mathrm{Pt}$ and $\mathrm{Pd}$, as well as the larger electronegativity of Pt than that of Pd [40], which is beneficial for the higher electrocatalytic activity. Thus, it is expected that the $\mathrm{Pd}_{52} \mathrm{Pt}_{48}$ catalyst exhibits the highest activity among all the samples due to the optimized composition in this study. Furthermore, unlike the reported bimetallic catalysts listed in Table S4, the MOR activity of the dendritic $\mathrm{Pd}_{52} \mathrm{Pt}_{48}$ nanoparticle is comparable to that of several state-of-the-art electrocatalysts, such as the nanoporous twinned $\mathrm{Pd}_{75} \mathrm{Pt}_{25}$ [46] and PtRu nanodendrites [22], but higher than those of many reported electrocatalysts $[6-8,11,14,24,25,20,31,34]$.

The stability of the electrocatalysts with different $\mathrm{Pd} / \mathrm{Pt}$ ratios was also evaluated by continuous $\mathrm{CV}$ cycling in the $0.1 \mathrm{~mol} \mathrm{~L}^{-1} \mathrm{HClO}_{4}+1 \mathrm{~mol} \mathrm{~L}^{-1} \mathrm{CH}_{3} \mathrm{OH}$ solution. As shown in Fig. S6, it can be observed that the peak currents initially increase as a result of their exposed surface, which can adsorb impurities, then the currents gradually decrease with successive scans resulting from poisoning the electrode surface. To better evaluate the durability of these catalysts, the CV curves of all the catalysts after 500 cycles were determined. As illustrated in Fig. $7 \mathrm{a}$ and Fig. S5c, the $\mathrm{Pd}_{82} \mathrm{Pt}_{18}, \mathrm{Pd}_{69} \mathrm{Pt}_{31}, \mathrm{Pd}_{52} \mathrm{Pt}_{48}, \mathrm{Pd}_{36} \mathrm{Pt}_{64}$, and commercial $\mathrm{Pt} / \mathrm{C}$ and $\mathrm{PtRu} / \mathrm{C}$ catalysts show losses of $86 \%$, $41 \%, 38 \%, 65 \%, 60 \%$ and $39 \%$ after 500 cycles, respectively. Strikingly, the $\mathrm{Pd}_{52} \mathrm{Pt}_{48}$ and $\mathrm{Pd}_{69} \mathrm{Pt}_{31} \mathrm{NPs}$ retain a higher methanol oxidation current than the rest of the catalysts tested as well as that of $\mathrm{Pt} / \mathrm{C}$ catalyst due to the well-developed synergistic effect under this composition in this paper. In detail, on the basis of the previous work [28], Pd is more easily dissolved compared with Pt. With the continuous removal of $\mathrm{Pd}$ in the core through pinholes, the particles gradually shrink, and the rearrangement of Pt atoms on the surface forms a more uniform and thin Pt layer, which can then improve the stability of the core-shell structure. This finding is also in agreement with the one mentioned above. Then, the stability of all samples was also evaluated by chronoamperometry. The results are descripted in Fig. 7b and Fig. S5d. After a sharp drop in the initial period of about 100s, the current decays at a slow speed, and then approaches a flat line. This phenomenon is attributed to the intermediate carbonaceous residues, which can be effectively oxidized and removed leading to a sustainable electro-oxidation process.

Impressively, the $\mathrm{Pd}_{52} \mathrm{Pt}_{48}$ and $\mathrm{Pd}_{69} \mathrm{Pt}_{31}$ catalysts maintained the higher current within 1,000 s when compared with the other catalysts tested in consistency (Fig. 7a and Fig. S5c). The morphologies of the $\mathrm{Pd}_{52} \mathrm{Pt}_{48}$ and $\mathrm{Pt} / \mathrm{C}$ catalysts after durability tests were also examined by TEM, as shown in Fig. S7. The results reveal that the dendritic nanostructures of $\mathrm{Pd}_{52} \mathrm{Pt}_{48}$ samples are well maintained after 500 cycles, whereas the $\mathrm{Pt} / \mathrm{C}$ catalyst show significant aggregations, further confirming that $\mathrm{Pd}_{52} \mathrm{Pt}_{48} \mathrm{NPs}$ has better stability compared with the $\mathrm{Pt} / \mathrm{C}$ catalyst.

Given that $\mathrm{CO}$ poisoning tolerance is a significant indicator to further evaluate the performance toward MOR, three consecutive CVs were recorded for the $\mathrm{Pd}_{52} \mathrm{Pt}_{48} \mathrm{NPs}$ (Fig. 8a), Pt/C catalyst (Fig. 8b), and other PdPt catalysts (Fig. S8), respectively. As shown in Fig. 8 and Fig. S8, a sharp peak appears during the first scan, and then disappears in the subsequent scan, indicating that the adsorbed CO is completely oxidized during the first forward scan. The onset potential of $\mathrm{CO}$ oxidation is indicated by the dashed line on the left for these catalysts. As can be seen, the $\mathrm{Pd}_{82} \mathrm{Pt}_{18}(0.492 \mathrm{~V}), \mathrm{Pd}_{69} \mathrm{Pt}_{31}(0.463 \mathrm{~V}), \mathrm{Pd}_{52} \mathrm{Pt}_{48}$ $(0.451 \mathrm{~V})$, and $\mathrm{Pd}_{36} \mathrm{Pt}_{64}(0.482 \mathrm{~V})$ catalysts are much more negative than that of commercial $\mathrm{Pt} / \mathrm{C}(0.507 \mathrm{~V})$ catalyst, indicating the easier removal of $\mathrm{CO}$ from the surface of the dendritic PdPt catalysts. Additionally, the $\mathrm{CO}$ oxidation peak potentials are $0.887,0.809,0.823,0.803$, and $0.831 \mathrm{~V}$ for the $\mathrm{Pd}_{82} \mathrm{Pt}_{18}, \mathrm{Pd}_{69} \mathrm{Pt}_{31}, \mathrm{Pd}_{52} \mathrm{Pt}_{48}, \mathrm{Pd}_{36} \mathrm{Pt}_{64}$, and $\mathrm{Pt} / \mathrm{C}$ catalysts, respectively. The lower $\mathrm{CO}$ oxidation potential implies the better CO-tolerance capability of the
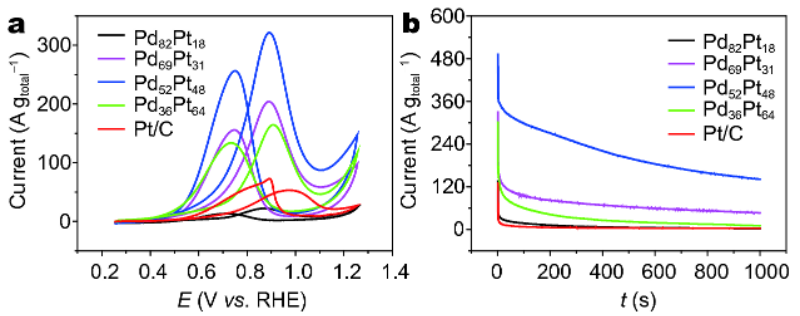

Figure 7 (a) CV curves of all the catalysts after 500 cycles in the solution of $0.1 \mathrm{~mol} \mathrm{~L}^{-1} \mathrm{HClO}_{4}+1 \mathrm{~mol} \mathrm{~L}^{-1} \mathrm{CH}_{3} \mathrm{OH}$ acquired at a scan rate of $50 \mathrm{mV} \mathrm{s}^{-1}$. (b) Chronoamperometry curves for all the catalysts in the $0.1 \mathrm{~mol} \mathrm{~L}^{-1} \mathrm{HClO}_{4}+1 \mathrm{~mol} \mathrm{~L}^{-1} \mathrm{CH}_{3} \mathrm{OH}$ at $0.816 \mathrm{~V}$ (vs. RHE) for $1,000 \mathrm{~s}$.

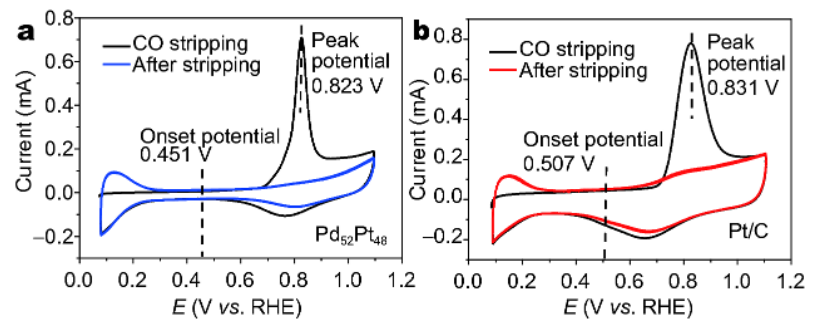

Figure 8 The CO stripping measurements of the (a) $\mathrm{Pd}_{52} \mathrm{Pt}_{48}$ and (b) commercial Pt/C catalysts in $0.1 \mathrm{~mol} \mathrm{~L}^{-1} \mathrm{HClO}_{4}$ at $50 \mathrm{mV} \mathrm{s}^{-1}$. 
catalyst, which arises from the dendritic structure and the synergistic effect due to the doping of the Pd atoms [27]. For the $\mathrm{Pd}_{82} \mathrm{Pt}_{18}$ catalyst, the larger peak potential may be due to the inapparent dendritic structure. Interestingly, although the $\mathrm{Pd}_{52} \mathrm{Pt}_{48}$ catalyst shows lower onset potential for $\mathrm{CO}$ removal than those of the $\mathrm{Pd}_{69} \mathrm{Pt}_{31}$ and $\mathrm{Pd}_{36} \mathrm{Pt}_{64}$ catalysts, it shows a slightly larger peak potential than those of the latter.

\section{CONCLUSIONS}

In summary, the as-made dendritic PdPt nanoparticles with tunable composition were fabricated by a one-step method, in which BT was used as both the reducing agent and surfactant. The binary compositions of these PdPt catalysts were controlled by simply adjusting the molar ratio of the Pd and Pt precursors. For MOR, these PdPt nanoparticles exhibited enhanced electrocatalytic performance. Especially, the $\mathrm{Pd}_{52} \mathrm{Pt}_{48}$ catalyst displayed the highest activities and much better durability, along with improved CO-resistance, making it superior to other $\mathrm{PdPt}$ samples and commercial $\mathrm{Pt} / \mathrm{C}$ catalysts. This is due to the dendritic PdPt catalysts having a highly open structure that allows accessible active sites at the surfaces as well as good electrical connection across the entire surface. On the other hand, the incorporation of $\mathrm{Pd}$ in $\mathrm{Pt}$ can modify the electronic structure of $\mathrm{Pt}$ due to the charge transfer from Pd to Pt resulting in a lower CO adsorption on the PdPt surface. The synergistic effect can be well-developed under the composition of $\mathrm{Pd}_{52} \mathrm{Pt}_{48}$ in this report. This context develops a simple and feasible route, which may be extended to the preparation of other bimetallic nanocrystals, thus making it possible to design highly active catalysts for fuel cells.

Received 30 September 2017; accepted 8 November 2017; published online 16 January 2018

1 Wang Y, Chen K, Mishler J, et al. A review of polymer electrolyte membrane fuel cells: technology, applications, and needs on fundamental research. Appl Energ, 2011, 88: 981-1007

$2 \mathrm{Fu} \mathrm{Q}, \mathrm{Li} \mathrm{H}, \mathrm{Ma}$ S, et al. A mixed-solvent route to unique PtAuCu ternary nanotubes templated from $\mathrm{Cu}$ nanowires as efficient dual electrocatalysts. Sci China Mater, 2016, 59: 112-121

3 Shang C, Yang M, Wang Z, et al. Encapsulated MnO in N-doping carbon nanofibers as efficient ORR electrocatalysts. Sci China Mater, 2017, 60: 937-946

4 Asiri H, Anderson A. Mechanisms for ethanol electrooxidation on $\mathrm{Pt}(111)$ and adsorption bond strengths defining an ideal catalyst. J Electrochem Soc, 2014, 162: F115-F122

5 Wu Y, Wang D, Li Y. Nanocrystals from solutions: catalysts. Chem Soc Rev, 2014, 43: 2112-2124

6 Huang D, Yuan Q, Wang H, et al. Facile synthesis of PdPt nanoalloys with sub-2.0 nm islands as robust electrocatalysts for methanol oxidation. Chem Commun, 2014, 50: 13551-13554

7 Lu Q, Wang H, Eid K, et al. Synthesis of hollow platinum-palladium nanospheres with a dendritic shell as efficient electrocatalysts for methanol oxidation. Chem Asian J, 2016, 11: 1939-1944

8 Zhan F, Bian T, Zhao W, et al. Facile synthesis of Pd-Pt alloy concave nanocubes with high-index facets as electrocatalysts for methanol oxidation. CrystEngComm, 2014, 16: 2411-2416

9 Lim B, Jiang M, Yu T, et al. Nucleation and growth mechanisms for Pd-Pt bimetallic nanodendrites and their electrocatalytic properties. Nano Res, 2010, 3: 69-80

10 Peng Z, Yang H. Synthesis and oxygen reduction electrocatalytic property of Pt-on-Pd bimetallic heteronanostructures. J Am Chem Soc, 2009, 131: 7542-7543

11 Wang L, Nemoto Y, Yamauchi Y. Direct synthesis of spatiallycontrolled Pt-on-Pd bimetallic nanodendrites with superior electrocatalytic activity. J Am Chem Soc, 2011, 133: 9674-9677

12 Zhang Z, Luo Z, Chen B, et al. One-pot synthesis of highly anisotropic five-fold-twinned $\mathrm{PtCu}$ nanoframes used as a bifunctional electrocatalyst for oxygen reduction and methanol oxidation. Adv Mater, 2016, 28: 8712-8717

13 Eid $\mathrm{K}$, Wang $\mathrm{H}, \mathrm{He} \mathrm{P}$, et al. One-step synthesis of porous bimetallic PtCu nanocrystals with high electrocatalytic activity for methanol oxidation reaction. Nanoscale, 2015, 7: 16860-16866

14 Fu G, Ma R, Gao X, et al. Hydrothermal synthesis of Pt-Ag alloy nano-octahedra and their enhanced electrocatalytic activity for the methanol oxidation reaction. Nanoscale, 2014, 6: 12310-12314

15 Xia T, Liu J, Wang S, et al. Nanomagnetic CoPt truncated octahedrons: facile synthesis, superior electrocatalytic activity and stability for methanol oxidation. Sci China Mater, 2017, 60: 57-67

16 Xia B, Wu H, Li N, et al. One-pot synthesis of Pt-Co alloy nanowire assemblies with tunable composition and enhanced electrocatalytic properties. Angew Chem Int Ed, 2015, 54: 3797-3801

17 da Silva S, Silva J, Buzzo G, et al. Electrochemical and fuel cell evaluation of $\mathrm{PtAu} / \mathrm{C}$ electrocatalysts for ethanol electro-oxidation in alkaline media. Int J Hydrogen Energ, 2014, 39: 10121-10127

18 Bian T, Zhang H, Jiang Y, et al. Epitaxial growth of twinned Au-Pt core-shell star-shaped decahedra as highly durable electrocatalysts. Nano Lett, 2015, 15: 7808-7815

19 Liu J, Chen B, Kou Y, et al. Pt-decorated highly porous flower-like Ni particles with high mass activity for ammonia electro-oxidation. J Mater Chem A, 2016, 4: 11060-11068

20 Wang Z, Lu C, Kong W, et al. Platinum nanoparticles supported on core-shell nickel-carbon as catalyst for methanol oxidation reaction. J Alloys Compd, 2017, 690: 95-100

21 Liu X, Cui C, Gong M, et al. Pt-Ni alloyed nanocrystals with controlled architectures for enhanced methanol oxidation. Chem Commun, 2013, 49: 8704-8706

22 Lee S, Park J, Park S. Roles of nitric acid treatment on PtRu catalyst supported on graphite nanofibers and their methanol electro-oxidation behaviors. Int J Hydrogen Energ, 2014, 39: 16468-16473

23 Li M, Zheng H, Han G, et al. Facile synthesis of binary PtRu nanoflowers for advanced electrocatalysts toward methanol oxidation. Catal Commun, 2017, 92: 95-99

24 Liu P, Yang D, Chen $\mathrm{H}$, et al. Discrete and dispersible hollow carbon spheres for PtRu electrocatalyst support in DMFCs. Electrochim Acta, 2013, 109: 238-244

25 Yang Z, Xu S, Xie J, et al. Effect of nitrogen-doped PtRu/graphene catalyst on its activity and durability for methanol oxidation. J Appl Electrochem, 2016, 46: 895-900

26 Ji Y, Wu Y, Zhao G, et al. Porous bimetallic Pt-Fe nanocatalysts 
for highly efficient hydrogenation of acetone. Nano Res, 2015, 8: 2706-2713

27 Antolini E. Palladium in fuel cell catalysis. Energ Environ Sci, 2009, 2: $915-931$

28 Sasaki K, Naohara H, Cai Y, et al. Core-protected platinum monolayer shell high-stability electrocatalysts for fuel-cell cathodes. Angew Chim Int Ed, 2010, 49: 8602-8607

29 Wu S, Zhu Y, Huo Y, et al. Bimetallic organic frameworks derived $\mathrm{CuNi} /$ carbon nanocomposites as efficient electrocatalysts for oxygen reduction reaction. Sci China Mater, 2017, 60: 654-663

30 Wang Q, Li Y, Liu B, et al. A facile reflux procedure to increase active surface sites form highly active and durable supported palladium@platinum bimetallic nanodendrites. J Power Sources, 2015, 297: $59-67$

31 Lai S, Fu C, Chen Y, et al. Pt-content-controlled synthesis of Pd nanohollows/Pt nanorods core/shell composites with enhanced electrocatalytic activities for the methanol oxidation reaction. J Power Sources, 2015, 274: 604-610

32 Liu $\mathrm{Q}, \mathrm{Xu} \mathrm{Y}$, Wang $\mathrm{A}$, et al. A single-step route for large-scale synthesis of core-shell palladium@platinum dendritic nanocrystals/reduced graphene oxide with enhanced electrocatalytic properties. J Power Sources, 2016, 302: 394-401

33 Mukerjee S, Srinivasan S, Soriaga M, et al. Effect of preparation conditions of Pt alloys on their electronic, structural, and electrocatalytic activities for oxygen reduction-XRD, XAS, and electrochemical studies. J Phys Chem, 1995, 99: 4577-4589

34 Zhang G, Huang C, Qin R, et al. Uniform Pd-Pt alloy nanoparticles supported on graphite nanoplatelets with high electrocatalytic activity towards methanol oxidation. J Mater Chem A, 2015, 3: 5204-5211

35 Huang X, Wu H, Liao X, et al. One-step, size-controlled synthesis of gold nanoparticles at room temperature using plant tannin. Green Chem, 2010, 12: 395-399

36 Ho Kim Y, Nakano Y. Adsorption mechanism of palladium by redox within condensed-tannin gel. Water Res, 2005, 39: 13241330

37 Ha W, Yu J, Wang R, et al. "Green" colorimetric assay for the selective detection of trivalent chromium based on Xanthoceras sorbifolia tannin attached to gold nanoparticles. Anal Methods, 2014, 6: 5720-5726

38 Zhang J, Wan L, Liu L, et al. PdPt bimetallic nanoparticles enabled by shape control with halide ions and their enhanced catalytic activities. Nanoscale, 2016, 8: 3962-3972

39 Fan F, Liu D, Wu Y, et al. Epitaxial growth of heterogeneous metal nanocrystals: from gold nano-octahedra to palladium and silver nanocubes. J Am Chem Soc, 2008, 130: 6949-6951

40 Gao H, Liao S, Liang Z, et al. Anodic oxidation of ethanol on coreshell structured Ru@PtPd/C catalyst in alkaline media. J Power Sources, 2011, 196: 6138-6143

41 Tan XH, Prabhudev S, Kohandehghan A, et al. Pt-Au-Co alloy electrocatalysts demonstrating enhanced activity and durability toward the oxygen reduction reaction. ACS Catal, 2015, 5: 15131524

42 Wang W, Huang Q, Liu J, et al. One-step synthesis of carbonsupported Pd-Pt alloy electrocatalysts for methanol tolerant oxygen reduction. ElectroChem Commun, 2008, 10: 1396-1399

43 Lu S, Eid K, Ge D, et al. One-pot synthesis of PtRu nanodendrites as efficient catalysts for methanol oxidation reaction. Nanoscale, 2017, 9: 1033-1039

44 Chen D, Tong YY. Irrelevance of carbon monoxide poisoning in the methanol oxidation reaction on a PtRu electrocatalyst. Angew Chem Int Ed, 2015, 54: 9394-9398

45 Lebedeva N, Rodes A, Feliu J, et al. Role of crystalline defects in electrocatalysis: CO adsorption and oxidation on stepped platinum electrodes as studied by in situ infrared spectroscopy. J Phys Chem B, 2002, 106: 9863-9872

46 Zhang X, Guan P, Malic L, et al. Nanoporous twinned PtPd with highly catalytic activity and stability. J Mater Chem A, 2015, 3: 2050-2056

Acknowledgements This work was supported by the National Natural Science Foundation of China (51571151, 51701139, 51671143, 51371119 and U1601216).

Author contributions Zhang Y and Zhang J designed and conceived the research framework; Zhang Y prepared and engineered the samples as well as conducted the performance investigation and so on; Chen $Z$ designed the Scheme 1; Zhang Y wrote the paper with support from Zhang J and Deng Y. All authors discussed the results and commented on the manuscript.

Conflict of interest The authors declare that they have no conflict of interest.

Supplementary information Supporting data are available in the online version of this paper, including additional TEM, HRTEM images, XRD patterns, the molecular structure and chemical properties of BT, $\mathrm{CV}$ curves of the current change for all the catalysts with the continuous cycling from the $1^{\text {st }}$ to $500^{\text {th }}$ cycle, EDX, ICP data, and the MOR activities of various catalysts, and so on. 

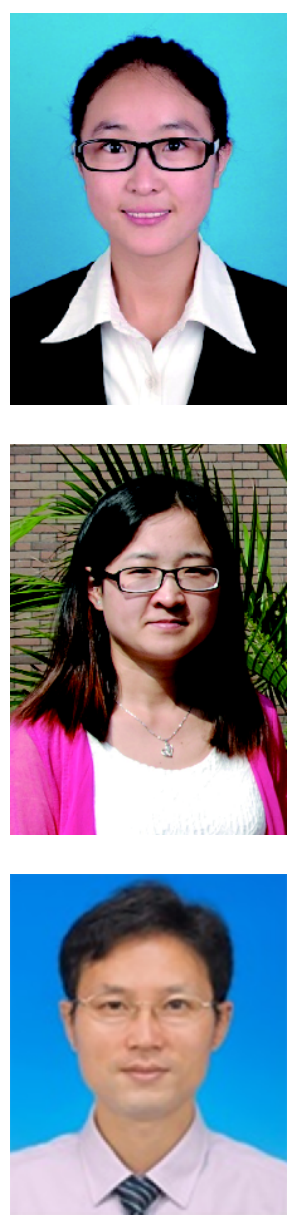

Yuan Zhang was born in 1992. She received her bachelor's degree from the School of Material Science and Engineering, Yanshan University, in 2015. She is now a graduate student at Tianjin University. Her research interests focus on the synthesis and characterization of platinum $(\mathrm{Pt})$-based nanomaterials for electrocatalytic applications.

Jinfeng Zhang received her PhD from the Department of Materials Science and Engineering, Shanghai Jiao Tong University, in 2016. She joined the Department of Materials Science and Engineering, Tianjin University in 2016. Her recent research interests focus on the design, synthesis, and characterization of nanostructured materials for electrocatalytic applications.

Yida Deng is a professor at the School of Materials Science and Engineering, Tianjin University. He received his PhD from Shanghai Jiao Tong University in 2006. His research interests include metal and metal oxide nanostructures for electrochemical and energy applications.

\section{具有枝状形貌的PdPt双金属纳米颗粒的甲醇氧化活性增强研究}

张媛, 张金风, 陈泽霖, 刘资威, 张萌萌, 韩晓鹏, 钟澄, 胡文涁, 邓意达 ${ }^{*}$

摘要 本文利用一步法制备了具有小粒径、组成可控和高催化活性的高度分散的枝状PdPt双金属纳米颗粒. PdPt双金属纳米颗粒通过单 宁酸 (BT)作为还原剂和表面活性剂得到, 起到了简化工艺的作用. 此外, 具有不同 $\mathrm{Pd} / \mathrm{Pt}$ 原子比的 PdPt双金属纳米颗粒可以通过改变 Pd和 $\mathrm{Pt}$ 前躯体的量来获得. 与其他成分 $\mathrm{PdPt}$ 纳米颗粒 $\left(\mathrm{Pd}_{82} \mathrm{Pt}_{18}, \mathrm{Pd}_{69} \mathrm{Pt}_{31}, \mathrm{Pd}_{36} \mathrm{Pt}_{64}\right)$ 和商业 $\mathrm{Pt} / \mathrm{C}(20 \mathrm{wt}$ \% $)$ 催化剂相比, $\mathrm{Pd}_{52} \mathrm{Pt}_{48}$ 催化剂具有最高的甲 醇氧化电催化活性, 这归因于其独特的树枝状结构以及 $\mathrm{Pd}$ 和Pt之间的协同效应. 该研究具有易于制备和高催化性能的优点, 在电化学能量 转换高性能催化剂方面具有巨大的应用前景. 